\title{
Influence of Processing Variables on the Pore Structure of Silica Gels Obtained with Tetraethylorthosilicate
}

\author{
Rúbia F. Silva, Wander L. Vasconcelos \\ Departamento de Engenharia Metalúrgica e de Materiais, \\ Universidade Federal de Minas Gerais, Belo Horizonte - MG, Brazil
}

Received: August 15, 1998; Revised: March 30, 1999

\begin{abstract}
In this work it was evaluated the influence of the type and concentration of the acid catalyst and the gelation temperature on the structure of pores of silica gels obtained with TEOS. The values of the major structural parameters related to the pores such as volume fraction of pore $\left(\mathrm{VV}_{\mathrm{V}}\right)$, surface area per unit volume $(\mathrm{SV})$, the average pore size ( $\mathrm{rP})$ and the connectivity of pores $(\mathrm{GV})$, obtained in this work showed the possibility of tailoring the pore structure of silica gels by changing the processing variables. For the HF catalyzed gels the values of average pore radius varied from 6.8 $\mathrm{nm}$ to $21.6 \mathrm{~nm}$, and the gelation time varied from $2 \mathrm{~min}$ to $140 \mathrm{~min}$. For the gels obtained in this work the activation energy for gelation (E) was found to be $11.8 \mathrm{kcal} / \mathrm{mole}$.
\end{abstract}

Keywords: silica, sol-gel, nanostructure

\section{Introduction}

A new generation of ceramic materials of high structural and unique properties has been emerged with the sol-gel processing, due to the possibility of manipulation and control of the nanostructure, which occurs from the first stages of the gel formation ${ }^{1-3}$.

Porous membranes have been used in separation processes of mixtures, solutions and suspensions involving species of different sizes and chemical nature. These applications require the use of porous materials with specific structural characteristics ${ }^{4}$.

The sol-gel processing is considered to be the most practical one for ceramic membrane synthesis, specially due to the possibility of designing the geometry of the pore network and the feasibility of obtaining narrow pore size distributions. Thus, acting in the processing conditions, one can change the pore structure and adapt the permeability of the silica monoliths to the different separation process desired $^{4,5}$.

In this work it is carried out an analysis of the porous structure of silica gels obtained via hydrolysis of tetraethylortosilicate (TEOS). It was evaluated the influence of the acid catalyst and the gelation temperature on the structural parameters of the silica gels.

\section{Experimental}

Sol-gel silica was prepared by acid catalysis of tetraethylortosilicate (TEOS, Aldrich Corp.) and deionized water, with ethanol (Merck Corp.) used as solvent. As catalyst, nitric acid $\left(\mathrm{HNO}_{3}\right.$, Merck Corp.), hydrofluoric acid (HF, Merck Corp.) and hydrochloric acid (HCl, Merck Corp.) were used. The molar ratio $\mathrm{H}_{2} \mathrm{O} / \mathrm{TEOS}$ was 16 and molar ratio ethanol/TEOS was 6 .

The sols were cast into cylindrical containers. The gelation of the sols obtained via $\mathrm{HCl}, \mathrm{HNO}_{3}$ and various concentrations of $\mathrm{HF}$ occurred at room temperature. In order to study the influence of the gelation temperature in the structural parameters of the silica gel, the gelation was also carried out at different temperatures, for gels catalyzed with a mixture of $\mathrm{HNO}_{3}(\mathrm{pH}=1.5)$ and $\mathrm{HF}(0.03 \mathrm{M})$. In this set of experiments, the gelation temperatures used were $27{ }^{\circ} \mathrm{C}, 40{ }^{\circ} \mathrm{C}, 50{ }^{\circ} \mathrm{C}$ e $60{ }^{\circ} \mathrm{C}$.

The aging of the gels was carried out at $60{ }^{\circ} \mathrm{C}$ during $48 \mathrm{~h}$. The drying was made at $80{ }^{\circ} \mathrm{C}$ during $48 \mathrm{~h}$. After drying the samples were analyzed using an automatic gas sorption machine (Autosorb 1, Quantachrome Corp.) for specific volume, specific surface area and average pore size. Bulk density was evaluated by mercury pycnometry.

The gelation time $\left(\mathrm{t}_{\mathrm{gel}}\right)$ was arbitrarily taken as the time at which the viscosity of solution increased suddenly. The viscosity measurements were performed in a viscosimeter with agitation velocity and temperature control $(\eta \mathrm{Re}-$ alogic).

The monolithicity was evaluated using the ratio between the weight of the largest entire part of the gel and the total weight of the gel after drying.

e-mail: rubia@demet.ufmg.br 


\section{Results}

\subsection{Influence of the type and concentration of the catalyst}

The values of $\mathrm{pH}$, gelation time ( $\left.\mathrm{t}_{\mathrm{gel}}\right)$ (at room temperature), specific surface area $\left(S_{P}\right)$, specific pore volume $\left(V_{P}\right)$ and average pore radius ( $\mathrm{r}_{\mathrm{P}}$ ) for the silica gels obtained via acid catalysis of TEOS using $\mathrm{HNO}_{3}, \mathrm{HCl}$ and $\mathrm{HF}$, with an acid/TEOS molar ratio (M) of 0.1 , are listed in Table 1. Table 2 presents the data obtained for $t_{g e l}, S_{P}, V_{P}$ and $r_{P}$ for gels fabricated with TEOS and catalyzed with $\mathrm{HNO}_{3}(\mathrm{pH}$ $=1.5$ ) and $\mathrm{HF}$ (with concentrations of $0.02 ; 0.03 ; 0.04$; $0.06 ; 0.08$ and $0.12 \mathrm{M}$ ). The variation of $t_{g e l}$ and $r_{P}$ with $\mathrm{HF}$ concentration are shown in Fig. 1 and Fig. 2, respectively. Table 3 presents the data on volume fraction of pores $\left(\mathrm{V}_{\mathrm{V}}\right)$, solid-pore surface area per unit volume $\left(\mathrm{S}_{\mathrm{V}}\right)$, genus $\left(\mathrm{G}_{\mathrm{V}}\right)$ and permeability $\left(\mathrm{K}_{\mathrm{P}}\right)$ for the silica gels.

\subsection{Influence of the gelation temperature}

The values of the processing variables and the physical properties of the silica gels obtained with the various gelation temperatures are shown in Table 4. Fig. 3 shows the relation between gelation time and gelation temperature obtained in this work.

\section{Discussion}

Commonly, $\mathrm{t}_{\text {gel }}$ can be decreased by processing parameters that increase the condensation rate ${ }^{5,7}$. For silica gels, gelation is typically faster in the presence of a base or HF than when using other acids, as indicated in Table 1. The pore structure of the gels obtained in different conditions is quite different. The specific surface area of the gels varied from $727 \mathrm{~m}^{2} / \mathrm{g}\left(\mathrm{HNO}_{3}\right)$ to $98 \mathrm{~m}^{2} / \mathrm{g}(\mathrm{HF})$. The specific volume of pores changed from $0.42 \mathrm{~cm}^{3} / \mathrm{g}\left(\mathrm{HNO}_{3}\right)$ to

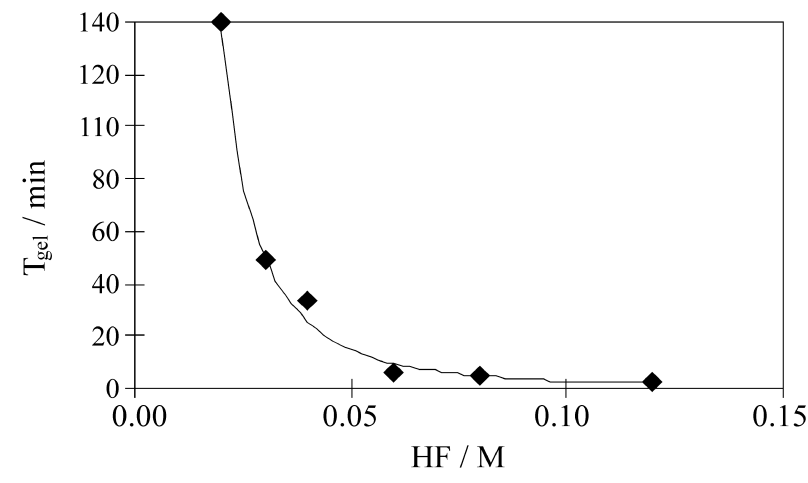

Figure 1. Gelation time as a function of HF concentration.

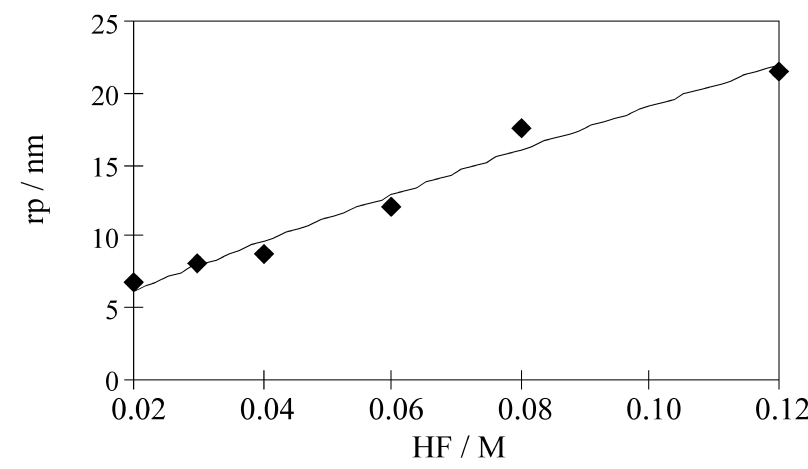

Figure 2. Average pore radius as a function of HF concentration.

Table 1. Values of gelation time (tgel), specific surface area ( $\mathrm{SP})$, specific pore volume (VP) and average pore radius (rP) for the silica gels obtained through acid catalysis of TEOS using $\mathrm{HCl}, \mathrm{HNO}_{3}$ and $\mathrm{HF}$.

\begin{tabular}{lccccc}
\hline Acid acid/TEOS $=0.1$ & $\mathrm{pH}$ & $\begin{array}{c}\mathrm{t}_{\mathrm{gel}} \\
(\mathrm{min})\end{array}$ & $\begin{array}{c}\mathrm{S}_{\mathrm{p}} \\
\left(\mathrm{m}^{2} / \mathrm{g}\right)\end{array}$ & $\begin{array}{c}\mathrm{V}_{\mathrm{p}} \\
\left(\mathrm{cm}^{3} / \mathrm{g}\right)\end{array}$ & $\begin{array}{c}\mathrm{r}_{\mathrm{p}} \\
(\mathrm{nm})\end{array}$ \\
\hline $\mathrm{HNO}_{3}$ & 0.5 & $2880 \pm 60$ & $727 \pm 22$ & $0.42 \pm 0.02$ & $1.2 \pm 0.1$ \\
$\mathrm{HCl}$ & 0.8 & $660 \pm 10$ & $532 \pm 16$ & $0.85 \pm 0.04$ & $3.2 \pm 0.1$ \\
$\mathrm{HF}$ & 1.5 & $9.0 \pm 0.1$ & $98 \pm 3$ & $1.56 \pm 0.08$ & $31.6 \pm 1.3$ \\
\hline
\end{tabular}

Table 2. Values of gelation time ( $\left.\mathrm{tgel}_{\mathrm{g}}\right)$, specific surface area $\left(\mathrm{SP}_{\mathrm{P}}\right)$, specific pore volume $\left(\mathrm{V}_{\mathrm{P}}\right)$, average pore radius $(\mathrm{rP})$ and bulk density $(\rho \mathrm{V})$ of silica gels catalyzed by mixtures of $\mathrm{HNO}_{3}$ and $\mathrm{HF}$ at different concentrations.

\begin{tabular}{lccccc}
\hline $\mathrm{HF}(\mathrm{mol} / \mathrm{L})$ & $\begin{array}{c}\text { tgel } \\
(\mathrm{min})\end{array}$ & $\begin{array}{c}\mathrm{S}_{\mathrm{p}} \\
\left(\mathrm{m}^{2} / \mathrm{g}\right)\end{array}$ & $\begin{array}{c}\mathrm{V}_{\mathrm{p}} \\
\left(\mathrm{cm}^{3} / \mathrm{g}\right)\end{array}$ & $\begin{array}{c}\mathrm{r}_{\mathrm{p}} \\
(\mathrm{nm})\end{array}$ & $\begin{array}{c}\rho_{\mathrm{V}} \\
\left(\mathrm{g} / \mathrm{cm}^{3}\right)\end{array}$ \\
\hline 0.02 & $140 \pm 7$ & $360 \pm 10$ & $1.21 \pm 0.05$ & $6.8 \pm 0.3$ & $0.65 \pm 0.01$ \\
0.03 & $49 \pm 3$ & $305 \pm 9$ & $1.23 \pm 0.06$ & $8.1 \pm 0.3$ & $0.54 \pm 0.01$ \\
0.04 & $33 \pm 2$ & $344 \pm 10$ & $1.49 \pm 0.07$ & $8.7 \pm 0.3$ & $0.54 \pm 0.03$ \\
0.06 & $6.0 \pm 0.3$ & $268 \pm 8$ & $1.61 \pm 0.08$ & $12.0 \pm 0.5$ & $0.55 \pm 0.01$ \\
0.08 & $5.0 \pm 0.1$ & $168 \pm 5$ & $1.50 \pm 0.07$ & $17.5 \pm 0.7$ & $0.53 \pm 0.01$ \\
0.12 & $2.0 \pm 0.1$ & $148 \pm 4$ & $1.60 \pm 0.08$ & $21.6 \pm 0.9$ & $0.51 \pm 0.01$ \\
\hline
\end{tabular}


Table 3. Values of volume fraction of pores $\left(\mathrm{VV}_{\mathrm{V}}\right)$, solid-pore surface area per unit volume $\left(\mathrm{SV}_{\mathrm{V}}\right)$, genus $\left(\mathrm{GV}_{\mathrm{V}}\right)$ and permeability $\left(\mathrm{K}_{\mathrm{P}}\right)$ for the silica gels catalyzed with $\mathrm{HNO}_{3}$ and $\mathrm{HF}$.

\begin{tabular}{lcccc}
\hline $\begin{array}{l}\mathrm{HF} \\
(\mathrm{mol} / \mathrm{L})\end{array}$ & $\mathrm{V}_{\mathrm{v}}$ & $\begin{array}{c}\mathrm{S}_{\mathrm{v}} \\
\left(10^{6} \mathrm{~cm}^{-1}\right)\end{array}$ & $\begin{array}{c}\mathrm{G}_{\mathrm{v}} \\
\left(10^{16} \mathrm{~cm}^{-3}\right)\end{array}$ & $\begin{array}{c}\mathrm{K}_{\mathrm{p}} \\
\left(10^{-14} \mathrm{~cm}^{2}\right)\end{array}$ \\
\hline 0.02 & $0.79 \pm 0.04$ & $2.34 \pm 0.10$ & $75.9 \pm 18.4$ & $4.6 \pm 0.7$ \\
0.03 & $0.66 \pm 0.04$ & $1.67 \pm 0.08$ & $20.7 \pm 5.8$ & $5.5 \pm 0.8$ \\
0.04 & $0.80 \pm 0.08$ & $1.86 \pm 0.16$ & $40.6 \pm 18.6$ & $7.6 \pm 1.3$ \\
0.06 & $0.89 \pm 0.06$ & $1.47 \pm 0.07$ & $31.4 \pm 8.8$ & $15.9 \pm 2.4$ \\
0.08 & $0.80 \pm 0.05$ & $0.89 \pm 0.04$ & $4.3 \pm 1.2$ & $30.4 \pm 4.4$ \\
0.12 & $0.82 \pm 0.06$ & $0.75 \pm 0.06$ & $2.8 \pm 0.8$ & $47.6 \pm 7.3$ \\
\hline
\end{tabular}

Table 4. Values of gelation time ( $\mathrm{tgel}_{\mathrm{gel}}$, monolithicity, specific surface area $\left(\mathrm{S}_{\mathrm{P}}\right)$, specific pore volume $\left(\mathrm{V}_{\mathrm{P}}\right)$, average pore radius $\left(\mathrm{r}_{\mathrm{P}}\right)$ and bulk density $\left(\rho_{\mathrm{V}}\right)$ of silica gels obtained with the various gelation temperatures.

\begin{tabular}{lcccccc}
\hline $\begin{array}{l}\text { Gelation temperature } \\
\left({ }^{\circ} \mathrm{C}\right)\end{array}$ & $\begin{array}{c}\text { tgel } \\
(\mathrm{min})\end{array}$ & $\begin{array}{c}\text { Monolithicity } \\
(\%)\end{array}$ & $\begin{array}{c}\mathrm{S}_{\mathrm{p}} \\
\left(\mathrm{m}^{2} / \mathrm{g}\right)\end{array}$ & $\begin{array}{c}\mathrm{V}_{\mathrm{p}} \\
\left(\mathrm{cm}^{3} / \mathrm{g}\right)\end{array}$ & $\begin{array}{c}\mathrm{r}_{\mathrm{p}} \\
(\mathrm{nm})\end{array}$ & $\begin{array}{c}\rho \mathrm{v} \\
\left(\mathrm{g} / \mathrm{cm}^{3}\right)\end{array}$ \\
\hline $27 \pm 1$ & $49 \pm 2$ & $94 \pm 3$ & $305 \pm 9$ & $1.23 \pm 0.06$ & $8.1 \pm 0.3$ & $0.54 \pm 0.01$ \\
$40 \pm 1$ & $40 \pm 2$ & $100 \pm 1$ & $461 \pm 14$ & $1.65 \pm 0.08$ & $7.2 \pm 0.3$ & $0.65 \pm 0.01$ \\
$50 \pm 1$ & $14.1 \pm 0.2$ & $100 \pm 1$ & $382 \pm 11$ & $1.34 \pm 0.07$ & $7.0 \pm 0.3$ & $0.64 \pm 0.01$ \\
$60 \pm 1$ & $7.1 \pm 0.1$ & $94 \pm 3$ & $314 \pm 9$ & $1.13 \pm 0.06$ & $7.2 \pm 0.3$ & $0.64 \pm 0.01$ \\
\hline
\end{tabular}

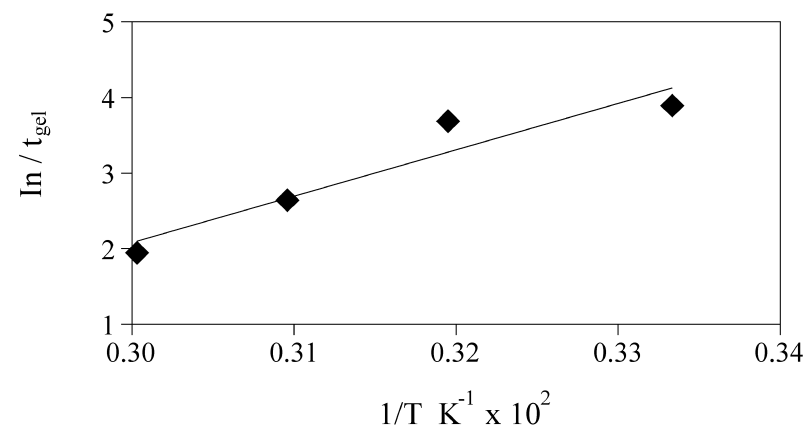

Figure 3. Gelation time as a function of gelation temperature.

$1.56 \mathrm{~cm}^{3} / \mathrm{g}(\mathrm{HF})$ and the pore radii changed from $1.2 \mathrm{~nm}$ $\left(\mathrm{HNO}_{3}\right)$ to $31.6 \mathrm{~nm}(\mathrm{HF})$.

The presence of HF has a strong influence on gelation time. Iler ${ }^{7}$ proposes that the polymerization process involves, temporarily, the expansion of coordination number of silicon from 4 to 5 or 6 , and the effectiveness in the polymerization process of the fluorine anion is due to its smaller ionic radius compared to that of the hydroxyl group. According to the Iler theory, the polymerization reaction is catalyzed by hydroxyl groups at $\mathrm{pH}$ 's greater than 2 , while for smaller $\mathrm{pH}$, the polymerization rates are proportional to the $\mathrm{H}^{+}$and $\mathrm{F}^{-}$ionic concentrations. It can be seen from Table 2 that as the concentration of HF changes from $0.02 \mathrm{M}$ up $0.12 \mathrm{M}$ the values of $\mathrm{r}_{\mathrm{P}}, \mathrm{S}_{\mathrm{P}}$, and $\mathrm{V}_{\mathrm{P}}$ vary significantly. That means that the presence of HF introduces a different structural arrangement of the pore structure, probably, due to the action of fluoride ions. It can be seen through Fig. 1, that the gelation time was found to vary between $2 \mathrm{~min}$ to 140 min. The average pore size increased for higher HF concentration, ranging from $6.8 \mathrm{~nm}$ to $21.6 \mathrm{~nm}$, as can be seen through Fig. 2.

It can be noted by Table 3 that the pore connectivity or genus $\left(G_{V}\right)$ is quite high. The values of $G_{V}$ were obtained by using a geometric model proposed by Vasconcelos ${ }^{6}$. In that model, the expression used to evaluate the genus is obtained through correlating of the metric properties $S_{V}$ and $\mathrm{V}_{\mathrm{V}}$, as follows ${ }^{6}$ :

$$
\mathrm{G}_{\mathrm{V}}=\frac{\mathrm{S}_{\mathrm{V}}{ }^{3}}{32 \pi \mathrm{V}_{\mathrm{V}}\left(1-\mathrm{V}_{\mathrm{V}}\right)}+1
$$

The coefficient of permeability $\left(\mathrm{K}_{\mathrm{P}}\right)$ is commonly used to represent the intrinsic component of permeability. The representation of $K_{P}$ using in this work is the following ${ }^{8}$ :

$$
\mathrm{K}_{\mathrm{p}}=\frac{\mathrm{V}_{\mathrm{V}} \mathrm{r}_{\mathrm{p}}^{2}}{16 \mathrm{c}}
$$

where $\mathrm{c}$ is a constant (with a value of 8 for cylindrical pores).

As shown in Table 3, GV decreases as the HF concentration increases, on the contrary of the permeability, which increases for higher HF concentrations. This result can be related to the fact that $G_{V}$ is very high for all samples, which allows for the stronger effect of the larger values of $r_{P}$ and 
$\mathrm{V}_{\mathrm{V}}$ associated to the samples with larger concentration in HF.

Since the hydrolysis and condensation reactions are thermally actived, as the temperature increases the gelation time decreases ${ }^{5}$, as can be seen by Fig. 3. The temperature dependence of gelation can be represented by an Arrhenius equation:

$$
\ln \left(\mathrm{t}_{g e l}\right)=\mathrm{A}+\frac{\mathrm{E}}{\mathrm{RT}}
$$

where $\mathrm{A}$ is a constant, $\mathrm{R}$ is the ideal gas content, and $\mathrm{T}$ is temperature. The "activation energy", E, for silica gels is found to be $\sim 10-20 \mathrm{kcal} / \mathrm{mole}$, depending on the catalyst and alkoxy group ${ }^{5,7}$. For the gels obtained in this work, E is found to be $11.8 \mathrm{kcal} / \mathrm{mole}$.

The high values of monolithicity obtained for different gelation temperatures denote that the higher gelation temperatures used in this work seems not to be inducing gradients of temperature in the polymeric solutions, which could lead to a decrease in the mechanical strength of the gels.

The values of $\mathrm{V}_{\mathrm{p}}$ varied from $1.23 \mathrm{~cm}^{3} / \mathrm{g}$ for the temperature of $27{ }^{\circ} \mathrm{C}$ to $1.13 \mathrm{~cm}^{3} / \mathrm{g}$ for the temperature of $60{ }^{\circ} \mathrm{C}$, presenting a maximum of $1.65 \mathrm{~cm}^{3} / \mathrm{g}$ for the gelation temperature of $40^{\circ} \mathrm{C}$. It can be seen by Table 4 , a similar behavior of the specific surface area, which presents a maximum value of $461 \mathrm{~m}^{2} / \mathrm{g}$ for the gelation temperature of $40{ }^{\circ} \mathrm{C}$. In spite of the significant influence of the gelation temperature in the gelation time, it was not verified any special tendency in the values of structural parameters of the silica gel with the variation of the temperature, for the samples used in this work.

\section{Conclusions}

The gelation time was changed from $2 \mathrm{~min}$. to $140 \mathrm{~min}$. by varying the HF concentration. For the HF catalyzed gels the values of average pore radius varied from $6.8 \mathrm{~nm}$ to 21.6 nm. For the gels catalyzed with $\mathrm{HNO}_{3}$ and $\mathrm{HCl}$, the gelation time obtained was higher and the pore structure was finer than for the HF catalyzed gels.

The values of $G_{v}$ for $H F$ catalyzed gel denote the high interconnectivity of the pore structure. The large values of $\mathrm{K}_{\mathrm{p}}$ suggest the feasibility of using these gels as separation membranes.

The gelation temperature influences significantly the gelation kinetics. For the gels obtained in this work, the activation energy for gelation $(\mathrm{E})$ is found to be 11.8 $\mathrm{kcal} / \mathrm{mole}$.

The results obtained in this work denote the possibility of tailoring the pore structure of the silica gels by changing some process variables, which is necessary for making separation membranes and catalysis support.

\section{References}

1. Nanostructure Processing of Advanced Catalytic Materials. http://itri-loyola.edu/nano/us-r-n-d/0406.htm. July 15, 1998.

2. Raman, N.K.; Anderson, M.T.; Brinker, C.J. Chem. Mater., v. 8, p. 1682-1701,1996.

3. Dispersions and Coatings. http://itri.loyola.edu/nano/us-r-n-d/06.02.htm. July 15, 1998.

4. Chain, K.K.; Brownstein, A.M. Ceramic Bulletin, v. 70, n. 4, p. 703-707, 1991.

5. Brinker, C.J.; Scherer, G.W. Sol-Gel Science: the Physics and Chemistry of Sol-Gel Processing, Academic Press, San Diego, 1990.

6. Vasconcelos, W.L.; DeHoff, R.T.; Hench, L.L. J. Non-Cryst. Solids, v. 121, p. 124-127, 1990.

7. Iler, R.K. The Chemistry of Silica, John Wiley, New York, 1979.

8. Reed. J.S. Introduction to the Principles of Ceramic Processing John Wiley, New York, 1988. 